\title{
Four Secondary Teachers' Perspectives on Enhancing the Inclusion of Exceptional Students
}

\author{
Kyle Robinson \\ Queen's University
}

\begin{abstract}
In Canada little research has been conducted on inclusive education practices in secondary schools. The purpose of this study is to report, for a diverse group of four secondary school teachers in a single school board in southeastern Ontario, their descriptions of facilitating the inclusion of exceptional students in general classrooms. The four teachers were recruited using an email referral method. Each of them participated in a semi-structured interview about their educational roles and role expectations, and about their reported instructional methods for inclusion. Seven categories emerged from the analyzed data, and these were clustered to form three themes: Structures and People, Meeting Everyone's Needs, and Knowing Your Students. The findings suggest that the participants in this study were facilitating inclusion of exceptional students in regular classrooms by considering how the students' functional needs impact their learning; most considered the functional learning and assessment needs of all students, not just exceptional students.
\end{abstract}

Throughout North America, provincial and state departments of education emphasize the inclusion of exceptional students. In the United States, the National Center for Education Statistics (NCES) is the federal agency tasked with collecting and analyzing educational statistics. The NCES reports that the number of students supported by special education and inclusion programs has risen by $5 \%$, from $8.3 \%$ to $13.8 \%$ in recent years (U.S. Department of Education, 2015). Within Canada, the recent rise is much more dramatic, with one study suggesting the number has almost doubled, rising from $14 \%$ to $23 \%$ in a 10-year span (People for Education, 2015). This increase in the number of students receiving some special education attention has been accompanied by a rise in attention to 
special education with the publication of documents about inclusion by the various Ministries of Education around Canada, mainly in elementary grades (e.g., Learning for All [Ontario Ministry of Education (OME), 2013], Special Education Services [British Columbia Ministry of Education, 2016]). Most of these documents are well aligned with the context of elementary schools, where inclusion was first implemented (Bennett \& Wynne, 2006; OME, 2005). What is not clear is how relevant these documents are for providing guidance in the secondary context.

As any teacher who has taught in both settings can attest, the school cultures of elementary and secondary school are very different. Numerous studies have alluded to the fractured (sometimes called balkanized or siloed) nature of a secondary school; that is, the division of teachers into departments tends to discourage collaboration (e.g., Brady, 2008; Firestone \& Louis, 1999; Hargreaves \& Macmillan, 1995). Two Canadian researchers suggested that the departmental organization of secondary schools creates "marginalization of some students and some teachers, restrictions on professional learning, and crippling inflexibility in the face of social and educational change" (Hargreaves \& Macmillan, 1995, p. 165). Furthermore, the distinctive culture of secondary schools "contribute[s] to the development of status hierarchies among students... Special needs students are frequently regarded as 'anomalies' and are often considered to be at the bottom of the [hierarchy in high schools]" (Brady, 2008, p. 15). Finley (1984) found that the structure of high schools leads teachers to "prefer to isolate these [special needs] students from others," as well as preferring to "avoid them wherever possible" (as cited in Brady, 2008, p. 15); this finding has been supported in current research on students with exceptionalities participating in co-operative education and workplace learning courses (Hutchinson et al., 2011; Taylor et al., 2015).

Thus, there is a growing need to study which teaching practices are being used with exceptional learners in regular secondary classrooms; whether these practices are consistent with research, policy, and guidelines designed to create the best inclusive learning environment (Swanson, 2001); and how secondary teachers come to use these specific practices, whether that be through the documents produced by Ministries of Education or other methods.

\section{Inclusive Teaching Practices}

Researchers have developed several methods of including students with exceptionalities in the regular classroom. Many of these, notably co-teaching and response to intervention, have been tested and validated in numerous studies (e.g., Murwaski \& Swanson, 2001; Vaughn \& Fuchs, 2003). The following section describes inclusive teaching practices that are commonly used in elementary schools (Bennett \& Wynne, 2006). The practices detailed in this section are not meant to represent an exhaustive list of inclusive teaching practices, but are chosen because they are championed in OME publications (i.e., OME 2005, 2013a), the ministry responsible for education in the province of Ontario. The second section reviews what little research exists focusing on inclusion methods specifically in secondary schools in Canadian settings. 


\section{Inclusion in Elementary Schools}

Universal design for learning and differentiated instruction. Universal design for learning (UDL; sometimes called universal design for instruction) is drawn from a way of thinking about architecture and general design in order to create items and spaces that are "usable by all people to the greatest extent possible" regardless of differences (Mae, Hardie, \& Place, 1991, p. 2). UDL encompasses many different ways of adapting and modifying the learning experience to meet the needs of all learners. New understandings in the areas of brain development, student diversity, learning styles, and how students learn have necessitated the development of new instructional methods that conform to the principles of UDL. One of the emerging models, differentiated instruction (DI), considers Vygotsky's (1962) sociocultural theory of learning and his notion of the zone of proximal development (Subban, 2006). "To differentiate," explained Hall (2002), "is to recognize students' varying background knowledge, readiness, language, preferences in learning and interests, and to react responsively" (p. 2). DI presents an effective means of addressing variance in learners (Tomlinson, 2014).

Co-teaching. Co-teaching is often claimed to be one of the best methods of inclusive education (Friend \& Cook, 1992), and involves two teachers who "plan lessons and deliver instruction together" while sharing "responsibility for assessing students' mastery" (Friend \& Cook, 1992, p. 30). The two teachers take on different roles within a typical class; for example, one teacher may teach the entire class, while the second circulates, paying attention to the needs of students who are struggling to learn the lesson's content (Cook \& Friend, 1995). In their 2001 meta-analysis, Murwaski and Swanson (2001) set out to provide a synthesis of all quantitative data on the effectiveness of co-teaching. At its core, the meta-analysis attempted to "quantify the co-teaching literature in terms of the magnitude of treatment outcomes" (2001, p. 259). Their findings were not supportive of the claim that co-teaching is one of the best methods of inclusive education. The overall mean effect size reported by Murwaski and Swanson (2001) was only 0.40 (Cohen's $d$ ), which suggests that "co-teaching is a moderately effective procedure for influencing student outcomes" (p. 264).

Tiered instruction and assignments. Besides co-teaching, researchers have suggested the use of tiered instruction and assignments in order to accommodate the unique learning needs of students with exceptionalities. Tiered activities offer

\footnotetext{
opportunities for students to work at varying levels on tasks (and the associated assessment) drawn from the curriculum. This approach conforms to many of the common aspects of universal design for learning (UDL) as well as many of the goals (Robinson \& Hutchinson, 2014)
}

set out by assessment documents. Tiered instruction has also been described as the "meat and potatoes" of differentiated instruction (Adams \& Pierce, 2003; Tomlinson, 2014).

In tiered instruction, students work in groups, usually assigned by the teacher, to grasp a specific concept. Groups are based on the individual needs of the students, or they may be formed based on readiness levels, learning profile, or student interest (Adams \& Pierce, 2003). Tomlinson (2014) called tiered activities a "readiness-based strategy ... [allowing] all students to focus on essential knowledge, understandings, and skills, but at different levels of complexity, abstractness, open-endedness, and independence" (p. 133). 
A review of the literature found that there is no empirical research on the effectiveness of tiered instruction and assessment at any grade level; publications tend to be qualitative and focus on the potential benefits.

Response to intervention (RTI). RTI provides an alternative to the "wait to fail" model of diagnosing learning disabilities (LD) in school, whereby schools and school systems only provide special education support after students have failed to learn, and have fallen behind their peers. Rather than identifying based on deficit, RTI identifies students based on risk; this creates an identification system that is proactive rather than reactive (Vaughn \& Fuchs, 2003). Teaching and intervention under this system is tiered, and all students, regardless of the presence of an exceptionality, fall into one of three tiers of support. Tier 1, also referred to as Universal Programming, constitutes sound, evidence-based classroom teaching strategies that conform to principles of both DI and UDL (OME, 2013). When effectively applied, around $80 \%$ of students are able to learn and retain the content (Katz, 2012; Mattall, 2008).

Students who continue to struggle after receiving Tier 1 instruction are moved to Tier 2. Teaching in Tier 2 consists of more intensive instruction, which may include additional help during or after school (either from the classroom teacher or a tutor), extra homework, varied readings, or co-teaching support (OME, 2013). It is important to note, as Katz (2012) did, that "the interventions take place in the original classroom, over a set period of time, with different students involved, depending on the skill or concept being addressed" (p. 139). Around 15\% of students will learn the curriculum content using this method (Katz, 2012; Mattall, 2008).

Tier 3 is the final tier, which researchers suggest only about $5 \%$ of students will ever need to access; it involves intensive, individual instruction (Katz, 2012; Mattall, 2008). It is at this stage that students may be referred to educational psychologists for identification or diagnosis. Some inclusion researchers suggest that instruction could also be on study skills, or "learning strategies provided outside the content area classroom that will enable students to learn independently once they are in content area classes" (Cook \& Tankersley, 2013, p. 101).

\section{Inclusive Teaching Practices Used in Secondary Schools}

Comparatively, there has been little research focusing on the teaching practices of secondary school teachers when acting to enhance the education of exceptional students. In one of the few notable exceptions, Paterson (2007) studied five teachers' "in-flight" thinking, which he defined as "the thinking of teachers as they engage in classroom teaching" (p. 428), in inclusive classrooms in Australia and Canada. The participants were a mixture of middle school (Grade 8) and secondary school (Grade 9) teachers, and were chosen based on their previous experience teaching students with learning difficulties in inclusive classrooms. Through a combination of observation, semistructured interviews, and stimulated recall interviews, Paterson (2007) wrote that he was able to view teaching practices at a previously "unobservable cognitive level," finding that "participants were thinking not only about the whole class, but also about individual students, recognizing their experiences, personalities, skills, and preferences and making ongoing adjustments to the lesson in accordance with that recognition" (p. 432). Four of 
the five teachers demonstrated extensive knowledge of the learning needs of individual students with learning difficulties. Rather than focusing on the categories of exceptionalities, as they appear in the research and some of the documents (e.g., OME, 2004), these teachers adjusted their teaching, as is characteristic of DI, based upon the individual student's characteristics.

While Paterson (2007) focused on teachers teaching a variety of secondary subjects, Edwards (2000) focused on inclusive practices in secondary science classrooms. In interviewing and observing three science teachers within a single Ontario secondary school, Edwards (2000) looked for similarities in inclusive teaching practices, finding that all three participants shared six teaching strategies: (a) they created supportive environments; (b) they accommodated for individual differences; (c) they used activityoriented lessons; (d) they used a variety of teaching strategies; (e) they let students take responsibility for their own learning; and (f) they collaborated with other teachers. As in Paterson's (2007), teachers in Edwards's (2000) study used strategies consistent with DI, along with other student-oriented inclusive practices. Both these studies suggest that secondary teachers who teach inclusively may focus primarily on learning needs, rather than on categories of exceptionalities as recorded in students' individual education plans (IEPs; also called individual program plans or individual learning plans).

Research on inclusive teaching practices of Canadian secondary teachers is scarce. Edwards's (2000) and Paterson's (2007) represent the landscape of such research. There is, however, a wealth of information on practices that teachers could use in inclusive classrooms, and how they might choose to implement these practices - although none are aimed at secondary teaching exclusively.

\section{Purpose}

The purpose of this multiple-perspective case study is to describe the cases of four diverse secondary school teachers in a single school board in southeastern Ontario and how they report they facilitate the inclusion of exceptional students in general classrooms. In talking to secondary teachers about inclusion, I sought an understanding of how teachers create an inclusive space using the tools provided to them by the Ontario Ministry of Education (OME), as well as those provided by their individual schools and school districts. The paper describes how teachers collaborate with other educators as well as what methods of inclusion classroom teachers use in facilitating the inclusion of exceptional students.

\section{Method}

This research used a multiple-perspective case study to describe the cases of four diverse secondary school teachers in Ontario and how they report facilitating the inclusion of exceptional students in regular classrooms. Case study allowed me to report these teachers' inclusive techniques and "bring about [an] understanding that in turn can affect and perhaps even improve practice" (Merriam, 1991, p. 32).

I recruited participants using purposeful selection techniques to target specific teachers who met the selection criteria; participants only needed to have taught in an 
Ontario secondary school and to have been involved in the planning of a course. Given these criteria, Bachelor of Education students who have only taught on practica were excluded, as were teachers who had only done work as an occasional teacher (also sometimes referred to as substitute teaching or a supply teacher). Teachers who had fulfilled long-term occasional teaching contracts (replacing a teacher for long periods, such as sabbaticals and maternity leaves) were included, as these teachers typically have planned the course from scratch and have access to student records and IEPs. Potential participants were then sent email messages containing an invitation to participate in the study, along with letters of information and consent forms. The emails also included a request that recipients forward them to fellow teachers who the recipients felt met the selection criteria.

\section{Participants}

Eventually, four teachers responded to the emails, and I arranged initial interviews. For a brief snapshot of each of the participants, refer to Table 1. The participants have been given pseudonyms to ensure anonymity. At the time of data collection, all four participants taught in the same school board, located in southeastern Ontario. This school board services students from rural, suburban, and urban areas. The board is spread over a large geographic area, and it services multiple counties and towns as well as a mid-sized city. As each participant's background and experience differed greatly from the others, this section provides a brief description of each participant, using words drawn from their interviews. These descriptions provide context for the findings of this research, and for the experiences each participant reported (Patton, 2002).

\section{Table 1}

Participants Demographic Information

\begin{tabular}{|c|c|c|c|c|c|c|c|}
\hline Pseudonym & Sex & Age & $\begin{array}{c}\text { Years of } \\
\text { Experience }\end{array}$ & $\begin{array}{l}\text { Teaching } \\
\text { Subjects }\end{array}$ & $\begin{array}{l}\text { Grades } \\
\text { Taught }\end{array}$ & $\begin{array}{c}\text { Schools } \\
\text { Taught } \\
\text { At }\end{array}$ & AQs* Taken \\
\hline Claire & Female & $<30$ & 4 & $\begin{array}{l}\text { English, } \\
\text { Drama }\end{array}$ & $\begin{array}{c}9,10 \\
12\end{array}$ & 4 & $\begin{array}{c}\text { Guidance \& Career } \\
\text { Education, Part } 1\end{array}$ \\
\hline Erika & Female & $<30$ & 6 & $\begin{array}{l}\text { Music, } \\
\text { History }\end{array}$ & $9-12$ & 7 & $\begin{array}{c}\text { Special Education, } \\
\text { Part } 1 \& 2\end{array}$ \\
\hline Jack & Male & $<30$ & 4 & $\mathrm{n} / \mathrm{a}$ & 9,10 & 5 & $\mathrm{n} / \mathrm{a}$ \\
\hline Reese & Male & $>40$ & 20 & $\begin{array}{l}\text { English, } \\
\text { Geography, } \\
\text { History }\end{array}$ & $9-12$ & 11 & $\begin{array}{c}\text { Primary Division; } \\
\text { Computer Science; } \\
\text { Principal's } \\
\text { Qualification }\end{array}$ \\
\hline
\end{tabular}

${ }^{*} \mathrm{AQ}=$ Advanced qualification

Jack. Jack was a young graduate student in education at a mid-sized Ontario university with a faculty of education; at the time of the interview, he was less than 30 years of age. Although he graduated with his Bachelor of Education in 2011, and he immediately applied to become an Ontario Certified Teacher, he had spent the majority of the past four years working part time as an occasional teacher. Jack was qualified to teach in the primary/junior $(\mathrm{P} / \mathrm{J})$ panel (i.e., Kindergarten to Grade 6), although he had 
spent about two years teaching in secondary schools, including during his alternative practicum during his Bachelor of Education program. He viewed himself primarily as a $\mathrm{P} / \mathrm{J}$ teacher, although he had taught in a board-wide secondary school literacy program, which was run in "four or five different high schools." Jack explained that the program was "really remedial literacy instruction."

Claire. Like Jack, Claire was a graduate student in Education at a mid-sized Ontario university; she was also less than 30 years old. She graduated from her Bachelor of Education program in 2011, and she was certified to teach in the intermediate and senior (I/S) divisions (i.e., Grades 7-12) in both history and drama. She immediately entered the workforce, and had spent the previous four years substitute teaching, including a number of long-term occasional (LTO) positions in both her teachable subjects. Claire had also taught full time, although at the time of her interview, her course entitlement was on hold due to maternity leave. During her time as a full-time teacher, Claire taught as an English teacher and a resource teacher. She had "taught all grade levels, except for Grade 11."

Reese. Reese had been teaching for 20 years within the board, having graduated with his Bachelor of Education in 1995. He was in his mid-40s. He had taught courses in all grade levels and in all streams, and he was qualified to teach four subjects: English, history, geography, and computer science. Upon starting his career, he also did LTOs in science and in special education classrooms. He had taught at 11 different secondary schools. Since graduating from his Bachelor of Education program, he spent nine years as a vice principal at a secondary school. When interviewed, Reese had returned to classroom teaching.

Erika. Erika was an Ontario Certified Teacher, qualified to teach in the I/S division. She was also less than 30 years old. Having graduated from her Bachelor of Education program in 2009, Erika had six years of teaching experience at the time of her interview. Her teachable subjects were in music and history, although during her time as an LTO teacher she had taught in civics, careers, anthropology, sociology, psychology, and English. She had taught in classes ranging from Grade 9-12, and, when interviewed, she reported having taught at seven secondary schools within her board. Like Claire, Erika had entitlement to a single course a year (in music), and she supplemented that with LTOs.

\section{Data Collection and Analysis}

Each participant took part in an initial, audio-recorded, semi-structured interview, up to 60 minutes long. Questions revolved around the same general topics, but, due to the conversational nature of semi-structured interviews, individual questions were worded differently at times to get a better sense of the differing experience of each participant. Three clusters of questions asked teachers about their current practices: background, roles and role expectations, and instructional methods. The fourth cluster, a "magic wand" question, asked teachers to imagine what they would like to be provided with to facilitate the inclusion of exceptional students. I only requested a follow-up interview of Claire, the first teacher I interviewed, and asked questions designed to probe further for experiences Claire found relevant to the questions asked in the initial interview. I also asked clarification questions about terms she had used during the initial interview. 
All interview data were transcribed verbatim using a word processing program. After transcribing all four participants' interviews, I began the process of analyzing the data using Atlas.ti (MAC, version 1.0.22). Data were analyzed three separate times. Initially, interview transcripts were skimmed, one by one, for relevant information regarding each participant's teaching background. Quotes were pulled out from the interview data and stitched together to form the four participant descriptions contained earlier. This initial analysis enabled me to construct these descriptions, and to become intimately familiar with the data (Agar, 1980; Creswell, 2013).

After crafting the individual participant profiles, I started the process of formally analyzing the data. Initially, each case was analyzed individually: Claire, Jack, Reese, and then Erika. I used the method of constant comparison, whereby I compared "the already coded incidents ... with each other and with incidents not yet coded" (Bryant \& Charmaz, 2007, p. 194). Interviews from the other three participants were coded in the same manner, and in each case I used codes from the coded interviews and new codes emerging from the interview I was analyzing.

After the four interviews had been coded, I began to group these codes into larger categories, and then later into themes. As per the suggestion of Glaser and Strauss (1999), categories emerged from the data, rather than being forced upon it. As I reviewed each code, I placed it within the category that most represented the initial intention of the code. After I finished categorizing the codes from the first interview, I continued to categorize codes from the remaining interviews using categories derived from the initial interview. If a code did not fit into a previously established category, a new category was created. As categories emerged from the data, I continued to use the constant comparison method; however, I then began to compare both codes to category and category to category (Bryant \& Charmaz, 2007). Combining codes and using constant comparison resulted in seven categories (Table 2).

Table 2

Categories and Themes That Emerged from the Data

\begin{tabular}{ll}
\hline \multicolumn{1}{c}{ Theme } & \multicolumn{1}{c}{ Category } \\
\hline Structures and People & - Teamwork \\
& $\cdot$ Infrastructure for inclusion \\
& \\
Meeting Everyone's Needs & - Accommodations \\
& - Accepting/safe learning environment \\
Knowing Your Students & $\cdot$ Limitations of IEPs \\
& $\cdot$ Gathering student information \\
\hline
\end{tabular}

The final stage of analysis was to take the categories that had emerged from the data and cluster them into themes. Like the creation of categories, this stage was also done by hand. I began by printing out the categories on individual pieces of paper. I then compared them to my initial research purpose and questions, and began to group them 
into larger themes. This process generated three themes. Table 2 contains a list of the themes and their respective categories. After coding the data, all the themes and categories from each participant were analyzed in a cross-case analysis. Themes and categories were brought together to find the commonalities among these four teachers.

\section{Findings}

Three themes emerged from the data: (a) Structures and People, (b) Meeting Everyone's Needs, and (c) Knowing Your Students. The first theme, Structures and People, refers to the support offered to the participants either by their school board, administration, or fellow teachers. Participants also spoke about needs specific to a particular learning space or program. The second theme, Meeting Everyone's Needs, emerged from participants discussing the importance of using teaching methods that facilitate the inclusion of all students, regardless of a formally diagnosed disability. This includes students from different races or cultures, or students struggling due to short-term crises. The final theme, Knowing Your Students, developed from the importance the teachers placed on getting to know their students on more than a surface level. For these teachers, this involved mining various sources for further information on the students' needs, beyond what was available in the IEP.

Although these themes were found in the data provided by all four participants, each individual interview contained only six out of seven component categories. Four of the seven categories that emerged from the data were apparent in the interviews of all four participants. Table 3 contains a visual representation of which categories are present in each participant's data. The order in which participant findings are reported is deliberate; the most robust cases are presented first, and within each case the predominant theme is reported first.

Table 3

Themes and Categories as They Appear in Each Interview*

\begin{tabular}{|c|c|c|c|c|c|}
\hline \multirow[t]{2}{*}{ Theme } & \multirow[t]{2}{*}{ Category } & \multicolumn{4}{|c|}{ Participants } \\
\hline & & Claire & Jack & Reese & Erika \\
\hline \multirow[t]{2}{*}{ Structures and People } & Teamwork & & $x$ & $x$ & $x$ \\
\hline & Infrastructure for inclusion & $x$ & $x$ & $x$ & $x$ \\
\hline \multirow[t]{2}{*}{ Meeting Everyone's Needs } & Accommodations & $x$ & $x$ & $x$ & $x$ \\
\hline & DI/UDL & $\mathrm{x}$ & $x$ & $x$ & $x$ \\
\hline \multirow[t]{3}{*}{ Knowing Your Students } & Accepting/safe learning environment & $x$ & $x$ & $\mathrm{x}$ & \\
\hline & Limitations of IEPs & $x$ & & & $x$ \\
\hline & Gathering student information & $x$ & $x$ & $x$ & $x$ \\
\hline
\end{tabular}

* The prominent theme in each case is highlighted.

\section{Claire}

Knowing your students. Claire's description of her job as a teacher captures the heart of her story. She believed that she must "first of all, become aware of the students and what 
their needs are." Much of her two interviews provided specific examples of how she came to know her students and how she then used that information to tailor her teaching to meet their needs. Claire described a number of different ways that she obtained information about a student, both formally (such as reading a student's IEP or Ontario Student Record [OSR]) and informally (such as through conversations). Claire noted that the formal avenues of collecting student information were inadequate, causing her to search for the information she needs from other sources. "As a teacher," she explained:

[You] have to advocate and find the people to talk to, you have to call the parents, you have to ... talk to the student, or go and do some research on your own, to figure out where this kid is coming from, and you should be doing that if you're a good teacher.

In one example, Claire discussed searching for information about a young student in one of her classes who was currently being accommodated for her dyslexia through the use of a reader pen. Claire

went and talked to her parents, and [the student] didn't want to use that. Not because of stigma, but because it was confusing and it was too much work. And they suggested to just print the work on pink paper; it's a lot easier for her to see.

Meeting everyone's needs. Claire's desire to learn about her students and their needs allowed her to develop a teaching pedagogy that largely revolved around the need to provide engaging, safe learning environments for all students, and she went "by that mantra of what's good for one is good for all." Claire reported that as she planned her lessons, including how she might need to accommodate students, she continually thought about how she might reduce any stigma that might arise from the student's receiving an accommodation. For example, one student in her class needed handouts printed on coloured paper, which led Claire to realize that "it's easy ... to print pink for everybody, it doesn't identify her among her peers." This extended to other areas of instruction as well, as she found

that [she is] often inclined to give extra time to everybody, to give the carrels, the quiet space, you know, to everybody... That helps out with the piece about stigmatization, especially as students get older ... They need these things, but they don't want to be singled out.

By offering accommodations to every student, regardless of whether the student is identified as exceptional, Claire has found herself advocating for, and actively creating, a learning environment that is safe and accepting. She provided basic items in her class, such as an agenda, organizational tools, and a missed homework binder, and has found that these "contribute to a sense of comfort, that somebody is in charge, somebody knows what they are doing." Claire believed that if students "feel like someone understands them, or cares for them, they're going to be better [self-]advocates, they're going to be more comfortable."

Structures and people. Claire discussed how the infrastructure that existed within her school board could, at times, create challenges to including students with exceptionalities. These concerns focused mainly on barriers to implementing and supporting technology issues that arose within her teaching. As technology is being developed and implemented at a rapid rate, Claire felt she was unable to properly implement this technology into her lessons, and she felt unable to help students who 
struggled with the technology. She needed time to learn the intricacies of any piece of technology: "Release time would be great for that, where you're not feeling like you're using up your opportunities for [professional development]." This rapid technological change, combined with the wide variety of choices of assistive technology that can be assigned, also caused challenges. Claire discussed the need for standardized assistive technology, suggesting that boards need to decide on a set list of technologies available that cover the widest possible range of accommodations:

If they somehow sort of universalized that, and got [all the teachers] to learn about that ... I feel like maybe that being the reason [the students] don't always use [technology] is maybe they feel it's not something that I'm as familiar with as I could be. If I was more familiar, maybe they'd use it more.

\section{Jack}

Meeting everyone's needs. Jack was particularly proud of his ability to create a classroom that was safe, accepting, and inclusive while continuing to motivate his students. He saw the perfect classroom as being a second family, and he reminisced about one such class "especially near the end, where [we] feel like a family. I feel like I'm with my brother and my Mom and my Dad ... it's like everybody is there for each other, it's a collective." In order to create a community of learners who feel safe and accepted, Jack used many forms of DI and UDL. It was important to Jack that his classroom was tailored to the students within that space, because each student has certain "types of environments they seem to flourish within and environments [that] seem to detract from their learning." As a graduate student studying cognition, Jack had begun to understand "there is a lot of social cognition involved with learning and that can be really important for teachers to notice." And he knew that "what [he is] doing or the environment [can] really influence [students'] learning."

Knowing your students. Jack felt that his role, as a teacher, "is just to find a way to get to know my students ... if you know your students then you can find access points and you can find appropriate challenges for them." Accordingly, he felt the need to gather information about his students in as many ways as he could. In order to do this, Jack would hold individual student conferences where he could learn:

what they think they're good at and what they think they aren't good at. That is sometimes more important than what they actually are good at and what they actually aren't good at. Because what they think can set limitations or set directions for them.

He also liked to collect "[past] examples of their work" in order to gather knowledge of what other teachers believed the student could or could not do. Jack collected this data because he believed that having a deep understanding of your students is an integral part of any DI:

To me at the heart of DI is every student is at a different place. Every human being is different, right, everyone's at a different place, everyone's got different experiences.... I want to emphasize the challenge. I think that the challenge is just as important. 
Jack believed that for his students, "it's not just about where are they and what do they need, it's where can I push them to go next" to be the best they can be.

Structures and people. Jack had taught in several different high schools in the board; his unique role had given him insights into the secondary school context that many of the other participants in this study did not have access to. Jack found that within his program there was a need for teamwork among all levels of educators - the administration, the resource teachers, the classroom teachers, and the educational assistants (EA). There was a need for each role to be accountable to the other roles, as he noted the administrators would come "into the class at least once a day, and they would observe my teaching, and they would observe student learning, and the classroom environment, and the [EA], how they were doing." This created a "really great relationship" between administration and teachers. In his view, it is important that administrators hold teachers accountable, because Jack "would hope, if I wasn't doing my job properly, the administrator would come in and say, here's where you need to focus your attention, you're missing this completely, so [their job is] to hold me accountable, too."

Jack reported that he loved to co-teach, and he would love to be able to implement this strategy not just with other teachers. He "would love to see administration get involved and say, I used to love teaching this, and can we get together and work on it. Teachers working together." Although co-teaching was not occurring to the degree that Jack would like, he did note that teachers worked together to solve some problems. Rather than discussing teaching methods or content, Jack found that "what [I] do talk about sometimes is 'I'm having trouble with this student, I don't really know what I can do here ... can you think of something else that will work?' Kind of anecdotes to help each other grow."

\section{Reese}

Structures and people. Reese had taught at more than a dozen of the schools within his board, and he was able to discuss, in depth, the ways that the board facilitated the inclusion of exceptional students. Having been an administrator, Reese provided a unique perspective on the ways he believed that administrators and teachers can work together to facilitate inclusion. Administration plays a large role in teachers' responsibilitiesincluding inclusion - and Reese believed that "it's the accessible administrators that are the most effective ones." This means being available to help teachers in need, visit classrooms regularly, and communicate expectations clearly. But accessibility is not easy to accomplish - there is a delicate balance to be maintained, especially when it comes to communication. Reese explained that he understood that at times a teacher can forget

the administration has to balance a couple of different things that don't necessarily back my teaching. I think every administrator has to decide at what point do I need to share this information or should I share this information even though maybe it is sensitive ... I haven't worked with an administrator who is neglectful of trying to do the right thing for a student.

Meeting everyone's needs. Reese's goal was to create a learning environment that met everyone's needs. He reported that "the most important thing about being in my classroom is that [students] are engaged with what I'm doing at a particular time." 
Reese's philosophy on teaching students with exceptionalities, identified or not, differed in a nuanced way from the other participants, as he tried to "make sure that [he doesn't] do anything to exclude those students." He developed this idea further as he talked about his general inclusion strategy, which was based on "trying to be mindful of what it is that we ask students to do and to identify the barriers that would make it difficult for a student to do that." It is not enough to identify the barriers. Once he identified them, Reese worked to "get rid of those barriers or accommodate those barriers." Reese described using this strategy to include all students with and without exceptionalities, including students who may need temporary accommodations for issues such as mental health, family emergencies, and other short-term crises.

Reese strove to create a learning space within his classroom where all students felt accepted and safe. He reported doing this, in part, by considering "inclusion in the sense of culture and ethnicities and identities, but also inclusion in the terms of learning styles and other formal identifications or informal identifications that we see, just to get kids feeling comfortable and understanding." This fits with Reese's view that teachers need to do a better job of teaching "students about who they're in classes with." As students without exceptionalities (or students from differing races or cultures) may not understand what other students' experiences are, Reese deliberately talked "to students about inclusion and who might be in our [classroom.]" Reese described how he taught the class about the experiences of students with conditions like autism, without directly referring to a student in the class with this exceptionality:

[The student with autism] sometimes had unusual things to say because the [other] students were working at a different level of abstract thinking than he was able to ... We did a reading on what teenage cognitive development looks like. And [the parent] was quite willing to have that happen.

Throughout the lesson, Reese reported that he could see "that students were learning and making some connections to people that they are aware of, and that allows for [them to have] a little more empathy and sensitivity and understanding." In his view, students need this direct form of teaching about inclusion because teenagers can be self-centred, and "they just assume that everybody's exactly like they are ... and when you help teach the differences ... it just opens their eyes to the possibility that not everybody is exactly like they are." Teaching students about the differences among learners is not only creating an inclusive learning space, but it is also preparing students for the world outside of school. In the example provided by Reese, directly addressing inclusion was successful, and "it's something that [he's] going to try and do more and more of."

Knowing your students. In Reese's opinion, administrators must gather the information that teachers needed to do their jobs, especially when it came to the "informal information from students who are identified." The largest population administrators got to know was "high-risk exceptional students." Due to the high-risk nature of these students, it was especially important that administrators shared any information they had in a "timely manner." Reese described that the school administration gathered so much important information for teachers about exceptional students, that a unique relationship was formed between the two. Because of this, Reese believed that "administration serves those students well when they touch base in the 
classroom and come into the room and see how things are going." For this reason, he wished that administrators would visit more often to create an environment that felt safer for students. Administrators visiting classrooms also played a role in creating a team of educators working together to facilitate inclusion.

\section{Erika}

Structures and people. In Erika's opinion, there was little teamwork taking place in the board, either among teachers or among the various levels of educators. When asked what role the administration played in facilitating inclusion, Erika responded simply with "nothing. Not unless I have a behaviour concern." As she described her feelings, Erika noted, "They're usually pretty good with behaviour exceptionalities." However, Erika had also "had examples where I've tried to have admin help me deal with behaviour [issues] and [they] have not and said I should just do it myself." This quote explains how Erika experienced inclusion-she required support from others and felt she was not receiving it.

If the administration was unable to help, Erika found that working with her fellow teachers did not help her facilitate inclusion, either. The issue here was not that there was no co-teaching or co-planning going on, as Erika admitted that "almost every time I teach history or civics, it's co-taught and planned; only music is not." Furthermore, Erika explained that "I'm not qualified to teach English, so I needed a lot more support [from co-workers]." In those courses, she had seen times "where we go, like, minute by minute over each lesson. Other times ... we just have the same summative [assessment]." When it came to facilitating the inclusion of students with exceptionalities, however, Erika reported that her experience was that teachers did not have the time or the resources to accommodate or modify lessons for these students. She felt she was only able to provide the most basic of accommodations, which was allowing extra time.

Erika was also keen to point out that she felt there was a general lack of availability when it came to the resource room and the resource teacher. If she felt the need to send a student to the resource room, Erika found that there was no space to accommodate that student. It frustrated Erika, especially when she perceived that the lack of space was due to a general lack of resource teachers to help accommodate her students; in her opinion, the "problem is that there's however many hundreds of IEPs and one [resource] teacher."

Erika reported there was also a lack of information within the board on how to include students with exceptionalities, which Erika thought might be due to what she believed was a constantly changing focus within the board. Each year, "the board will come up with a buzz word, or concept, or whatever, like differentiated instruction or co-whatever teaching." And, although Erika felt that the teachers want to delve deeper into the topic, after six months to a year, the board comes up with another "buzz word" to focus on. Erika found this cycle to be never ending, and that the board was "throwing five terms at us and then we have to learn five more terms the next year, and it doesn't really [end]." Erika wished the board would "pick a concept" and allow teachers to "actually perfect it, and figure out how it works really well over the course of a couple years." Erika felt that she was unable to even grasp a concept before a new one was given to them. 
Meeting everyone's needs. Erika understood that her classroom was a place where all students need to learn, and there were students who require accommodations, even though they may not have a formal, or informal, IEP. She believed that her job was about "making [the classroom] a safe place." To do this, Erika made sure that, when she felt she could, she accommodated all students regardless of the presence of an exceptionality. For example, she reported giving "extra time to everybody." Similarly, she made sure that she only assessed what is necessary, such as when she does not "count spelling or grammar on [something] like a history test." In Erika's view, this "helps kids with IEPs because they know the content but [sometimes] it just doesn't come out the same way written down."

Erika's teaching pedagogy included a number of principles of DI and UDL, as she used a strategy called "gradual release. Usually, we'll do an example all together, so I'll have it on a computer and we'll talk through it, and it's on the projector screen, and they probably have a handout as well." Then, students gradually worked on the task independently. She also made sure she taught to "all different types of learning styles." Through these techniques Erika hoped to meet the learning needs of as many students as possible.

Knowing your students. Erika reported that there was a lack of information presented to her in sources such as IEPs and OSRs. Erika gathered any additional information she needed about students from one of two sources. First, she made sure that she was always "asking students ... what methods they prefer or find the clearest," and she subsequently modified her teaching methods to use those methods more. Erika talked about an instance when she was "teaching a theory lesson once and [the music students] were just not responding." Erika paused the lesson, and asked the students "why they weren't engaged in the lesson." Upon hearing the lesson was too hard, Erika reported that she "explained to them that it was my fault for making the lesson not clear and not their fault for not getting it." The next day, Erika decided to use "chunking," in which she "retaught it in a more broken up way, with smaller steps." However, Erika did note that she did not modify her teaching style to suit the needs of the students until after they were having difficulties. Erika also reported talking to colleagues, especially one particular teacher with whom she had cultivated a "mentor-type relationship."

\section{Discussion}

This study's goal was to describe how these four secondary school teachers facilitated inclusion in their regular education classrooms. The rest of this article discusses the four teachers as a whole, focusing on the ways the inclusive teaching methods reported by the participants both differ and overlap with the ones used in elementary schools.

\section{Different Inclusion Methods in Secondary}

Considerable evidence suggests that secondary school teachers' methods of including exceptional students in their regular classrooms, while similar to their elementary school colleagues, diverge in ways that further the methodological teaching divide between the two levels. Although these teachers did not refer to basic building blocks of inclusive teaching (such as DI or UDL) directly and were not familiar with their Ministry of Education's professional documents on inclusion, all four described teaching 
in inclusive ways. They described three main reasons for their inclusive teaching: inclusive practices are helpful to many while necessary for a few; they made classrooms feel safe and accepting; and these practices prevented students from being excluded or feeling stigmatized.

The four participants in the study discussed the need to know their students at a level that students' files (such as the IEP or OSR) did not allow. Jack and Claire - and to some extent, Reese-discussed getting to know the individual learning needs of their students and then catering their teaching to meet them. They largely ignored the label placed on students by an IEP and looked for information about the students' functional learning needs at any given time. This is in line with the International Classification of Functioning, Disability and Health (ICF; World Health Organization, 2001, 2007), which characterizes the functional needs of a disability as ever changing, based on a person's health and contextual factors. Jack, Claire, and Reese understood that students' learning needs change, often between annual identification, placement, and review committee (IPRC) meetings; and they constantly gathered information to understand the students' needs at any given moment. They then used a teaching method similar to that of Corno (2008) to adapt their teaching to the strengths of the students.

This finding extends beyond existing research, as the data strongly suggest these four teachers do not rely on the information contained within the IEP or OSR in order to understand a students' needs. Some go so far as to ignore the information, if they were able to access it at all. In order to gather key information, three of the four teachers go directly to primary sources, such as the student, the parent, and previous teachers. There is no previous research suggesting secondary school teachers are ignoring information provided to them by annual IEP or IPRC meetings, nor is there any that suggests they vigorously gather information on students' needs from multiple sources.

Although this study did not observe teaching practices in the classroom, participants reported teaching in ways that are similar to the findings of Paterson (2007), in that these teachers were thinking about the whole class while simultaneously recognizing the needs of the individual student. Reese, Erika, Jack, and Claire desired to create engaging, safe, and accepting learning environments for all students, which mirrors the teachers in Edwards' (2000) study, who also looked to create supportive environments. Reese, Jack, and Claire also reported using other teaching strategies that overlap with Edwards' (2000) findings, including letting students take more responsibility over their learning and collaborating with other teachers.

These four teachers recognize that to enhance inclusion they would benefit from more collaboration with their colleagues and administrators. While authors like Cook and Friend (1995) and Rice and Zigmond (2000) have suggested that collaboration and coteaching could be a cornerstone of inclusive teaching practices in secondary school, this study, and others such as Leithwood (2008), suggest this is difficult for teachers to accomplish in balkanized secondary schools. 


\section{Overlaps with Elementary School Methods}

Although many of the experiences reported by these teachers would have no counterparts in elementary grades, some of the methods of inclusive teaching reported here were originally developed for and used in the elementary school setting, such as DI and UDL (Bennett \& Wynne, 2006). All four teachers reported using principles of DI and UDL, although usually not with explicit reference to these approaches by name; only one participant used either term to describe their teaching methods, and only after probing.

Reese was using a form of tiered instruction when he grouped his classes by students' abilities. His use of the method is in line with research by Adams and Pierce (2003) and Servillo (2009), although he did not go into specifics on what tasks he assigns when using this method. Reese's use of choice, especially when assigning readings, is also seen in research by Servillo (2009).

Although research on RTI has been done in secondary schools (e.g., Vaughn \& Fletcher, 2012), none of the participants in this study reported using the method. Two teachers reported not knowing what RTI entails, suggesting that the findings of Sansosti, Goss, \& Noltemeyer (2011) hold true: that as it is currently conceptualized, RTI is not designed for secondary schools and their unique, departmentalized structure.

\section{Further Research}

Although this study follows Creswell's (2013) suggestion that a multiple-perspective case study should have "no more than four or five cases" (p. 101), it could easily be reconceived as a typical qualitative study in which seven to ten participants of diverse backgrounds are interviewed, and their data are analyzed together. In fact, that is how this study was initially conceived, before I settled on four participants. However, expanding the study to include more teachers would allow for more varied perspectives on how secondary school teachers include students with exceptionalities in their regular classrooms. It would also increase the chances that the participants would vary in their teaching subjects. Further research needs to seek participants who teach in subjects other than the humanities in order to create a more robust picture of the state of inclusive teaching in secondary schools. Future research also needs to be expanded to include participants from multiple school boards, in order to consider whether secondary school teachers are consistent across Canada, and, if they are not, what boards are doing to help their teachers to achieve different inclusive teaching methods.

Second, further research needs to be conducted on secondary school teachers' use and understanding of professional documents. Of the participants who had been employed as teachers in regular secondary school classrooms (Claire, Reese, and Erika), none of the three had any knowledge on the OME's recently released Learning for All (2013), a document designed and created for the purpose of helping teachers, both elementary and secondary, to include students with exceptionalities in their classrooms. While conducting this study, I found no literature on teachers' use of these documents, or on teachers' knowledge of the information contained within them. A study needs to be conducted that determines whether the cost (in both money and personnel) of producing professional documents such as Learning for All (OME, 2013) is justified by teachers' 
use of them. Further research also needs to be conducted on how to help teachers stay current, considering these documents, as currently devised and distributed, are not meeting the Ministry of Education's purpose in creating and distributing them.

The final recommendation for future research involves investigating the usefulness of the World Health Organization's $(2001,2007)$ as a means of enhancing teachers' inclusion of students with exceptionalities. As studies conducted in Portugal (e.g., Sanches-Ferreira, Silveira-Maia, \& Alves, 2014) attest, ICF can replace a psychoeducational diagnosis in special education with a description of the functional needs of the student. This may allow for more students to receive an IEP - formal or informal - as the wait for psycho-educational testing could be avoided. I could locate no studies attempting to determine whether ICF could be implemented successfully as part of Ontario's special education program.

\section{Limitations}

The small number of participants, all of whom were employed in a single school board, could limit how transferable and generalizable these findings are, since the information contained here may not be representative of the wider group of secondary school teachers. The group, while diverse, did not necessarily reflect a wide range of teaching experience or content areas. All four teachers taught in humanities classrooms, and three of them taught in some form of an English classroom; the perspectives of science teachers are not reported. As well, the participants did not represent a full spectrum of experience: three were all relatively new teachers with less than five years' experience, while one had 20 years' experience. In consequence there is no representation within this study of teachers who completed their Bachelor of Education program in the early 2000s, when full inclusion was becoming the norm in secondary schools (Bennett \& Wynne, 2006).

Because this study sought volunteers as participants, there was a chance that selfselection would favour teachers who held positive views on inclusion and exclude those with negative views or experiences Three of the four participants in the current study gave responses that were positive toward inclusion and inclusive methods, while the fourth was not as positive.

Finally, the nature of the study may have lead to participants' feeling some pressure of social desirability, the phenomenon in which research participants "attempt to act in ways that make them seem desirable to other people" (Furr, 2010, p. 1395). In this case, the participants may have given responses that were positive in an attempt to facilitate my research. However, the robust nature of the data suggests that the participants were giving responses that accurately reflected their beliefs and teaching practices.

\section{Conclusion}

This study represents a crucial starting point for examining the inclusive practices of secondary school teachers, a group desperately underrepresented in current research. Findings suggest that the four secondary teachers interviewed were striving to ensure that all students, not just those deemed exceptional, were included in their classrooms. They 
did this largely by adapting their teaching styles based on students' functional needs, rather than on how students were labelled. They determined the need to do this without the direct input of their ministries, as the professional documents produced by ministries of education were not used. Despite this, three of the four teachers used methods of inclusion that conform to the principles of DI and UDL.

\section{References}

Adams, C. M., \& Pierce, R. L. (2003). Teaching by tiering. Science and Children, 41(3), 30-34.

Agar, M. H. (1980). The professional stranger: An informal introduction to ethnography. New York, NY: Academic Press.

Bennett, S., \& Wynne, K. (2006). Special education transformation: The report of the co-chairs with the recommendations of the working table on special education. Toronto, ON: Queen's Printer for Ontario.

Brady, P. (2008). Working towards a model of secondary school culture. Canadian Journal of Educational Administration and Policy, 73, 1-26.

British Columbia Ministry of Education. (2016). Special education services. Victoria, BC: Author.

Bryant, A., \& Charmaz, K. (Eds.). (2007). The Sage handbook of grounded theory. London, UK: Sage. doi:10.4135/9781848607941

Cook, B. G., \& Tankersley, M. (2013). Research based practices in special education. Boston, MA: Pearson.

Cook, L., \& Friend, M. (1995). Co-teaching: Guidelines for creating effective practices. Focus on Exceptional Children, 28(3), 1-16.

Corno, L. (2008). On teaching adaptively. Educational Psychologist, 43, 161-173.

Creswell, J. W. (2013). Qualitative inquiry and research design: Choosing among five approaches (3rd ed.). Thousand Oaks, CA: Sage Publications.

Edwards, K. L. (2000). 'They can be successful too': Inclusive practices of secondary school science teachers (Master's thesis). Available from ProQuest Dissertations and Theses database. (Order No. MQ52896)

Firestone, W. A., \& Louis, K. S. (1999). Schools as cultures. In J. Murphy \& K. S. Louis (Eds.), Handbook of research on educational administration: A project of the American Educational Research Association (2nd ed., pp. 297-322). San Francisco, CA: Jossey-Bass Publishers.

Friend, M., \& Cook, L. (1992). The new mainstreaming: How it really works. Instructor, 101(7), 3037.

Furr, M. R. (2010). Social desirability. In N. J. Salkind (Ed.), Encyclopedia of research design (pp. 1395-1399). Thousand Oaks, CA: Sage.

Glaser, B. G., \& Strauss, A. L. (1999). The discovery of grounded theory: Strategies for qualitative research. Chicago, IL: Aldine Publishing Company.

Hall, T. (2002). Differentiated instruction. Wakefield, MA: National Center on Accessing the General Curriculum.

Hargreaves, A., \& Macmillan, R. (1995). The balkanization of teaching. In L. S. Siskin \& J. W. Little (Eds.), The subjects in question: Departmental organization and the high school (pp. 141171). New York, NY: Teachers College Press. 
Hutchinson, N. L., Versnel, J., Poth, C., Berg, D., deLugt, J., Dalton, C., ... Munby, H. (2011). "They want to come to school": Work-based education programs to prevent the social exclusion of vulnerable youth. Work, 40, 195-209.

Katz, J. (2012). Teaching to diversity: The three-block model of universal design for learning. Winnipeg, MB: Portage \& Main Press.

Leithwood, K. (2008). Working conditions: Experiences of elementary and secondary teachers in Ontario's public schools. Toronto, ON: Elementary Teachers' Federation of Ontario.

Mae, R. L., Hardie, G. J., \& Place, J. P. (1991). Accessible environments: Toward universal design. Raleigh, NC: The Center for Universal Design.

Mattall, C. (2008, June). Gauging the readiness of Canadian school districts to implement responsiveness to intervention. Paper presented at the annual meeting of the Canadian Society for the Study of Education, Vancouver, BC.

Merriam, S. B. (1991). Case study research in education: A qualitative approach. San Francisco, CA: Jossey-Bass Publishers.

Murwaski, W. W., \& Swanson, H. L. (2001). A meta-analysis of co-teaching research: Where are the data? Remedial and Special Education, 22(5), 258-267. doi:10.1177/074193250102200501

Ontario Ministry of Education. [OME]. (2005). Education for all: The report of the expert panel on literacy and numeracy instruction for students with special education needs, Kindergarten to Grade 6. Toronto, ON: Queen's Printer for Ontario.

Ontario Ministry of Education. [OME]. (2013). Learning for all: A guide to effective assessment and instruction for all students, Kindergarten to Grade 12. Toronto, ON: Queen's Printer for Ontario.

Paterson, M. (2007). Teachers' in-flight thinking in inclusive classrooms. Journal of Learning Disabilities, 40, 427-435. doi:10.1177/00222194070400050601

Patton, M. (2002). Qualitative research and evaluation methods. Thousand Oaks, CA: Sage Publications.

People for Education. (2015). Ontario's schools: The gap between policy and reality (Annual Report on Ontario's Publicly Funded Schools 2015). Toronto, ON: People for Education.

Rice, D., \& Zigmond, N (2000). Co-teaching in secondary schools: Teacher reports of developments in Australia and American classrooms. Resources in Education, 15, 190-197. doi:10.1207/SLDRP1504_3

Robinson, K., \& Hutchinson, N. L. (2014, August 6). Tiered approaches to the education of students with learning disabilities. Retrieved from the Learning Disabilities Association of Ontario website, LD@school, https://www.ldatschool.ca/tiered-approaches-to-the-education-ofstudents-with-learning-disabilities/

Sanches-Ferreira, M., Silveira-Maia, M., \& Alves, S. (2014). The use of the International Classification of Functioning, Disability and Health, version for Children and Youth (ICF$\mathrm{CY}$ ), in Portuguese special education assessment and eligibility procedures: The professionals' perceptions. European Journal of Special Needs Education, 29, 327-343. doi:10.1080/08856257.2014.908025

Sansosti, F. J., Goss, S., \& Noltemeyer, A. (2011). Perspectives of special education directors on response to intervention in secondary schools. Contemporary School Psychology, 15, 9-20.

Servillo, K. R. (2009). You get to choose! Motivating students to read through differentiated instruction. TEACHING Exceptional Children Plus, 5(5), 1-11. 
Subban, P. (2006). Differentiated instruction: A research basis. International Education Journal, 7, 935-947.

Swanson, L. (2001). Searching for the best model for instructing students with learning disabilities. Focus on Exceptional Children, 24(2), 1-15.

Taylor, C. E., Hutchinson, N. L., Ingersoll, M., Calton, C., Dods, J., Godden, L., ... deLugt, J. (2015). At-risk youth find work hope in work-based education. Exceptionality Education International, 25, 158-174.

Tomlinson, C. A. (2014). The differentiated classroom: Responding to the needs of all students. Alexandria, VA: ASCD.

U.S. Department of Education, National Center for Education Statistics. (2015). Digest of Education Statistics, 2013 (NCES 1015-011). Washington, DC: Author.

Vaughn, S., \& Fletcher, J. M. (2012). Response to intervention with secondary school students with reading difficulties. Journal of Learning Disabilities, 45, 244-256.

Vaughn S., \& Fuchs L. S. (2003). Redefining learning disabilities as inadequate response to instruction: The promise and potential problems. Learning Disabilities Research \& Practice, $18,137-146$.

Vygotsky, L. S. (1962). Thought and language. Cambridge, MA: MIT Press.

World Health Organization. (2001). International classification of functioning, disability and health. Geneva, Switzerland: Author.

World Health Organization. (2007). International classification of functioning, disability and health (Children \& youth version). Geneva, Switzerland: Author.

\section{Author's Note}

Correspondence concerning this article should be addressed to Kyle Robinson, Queen's University Faculty of Education, Duncan McArthur Hall, 511 Union Street, Kingston, ON, K7M 5R7, Canada. Email: kyle.robinson@queensu.ca 